\title{
EFEITOS DA GIBERELINA E DA SECAGEM NO CONDICIONAMENTO OSMÓTICO SOBRE A VIABILIDADE E O VIGOR DE SEMENTES DE MAMÃO (Carica papaya L.) ${ }^{1}$
}

\author{
HIGINO MARCOS LOPES ${ }^{2}$, CLEITON MATEUS SOUZA ${ }^{3}$
}

\begin{abstract}
RESUMO - Esta pesquisa teve como objetivo avaliar os efeitos da presença ou ausência de giberelina na solução de condicionamento osmótico e da secagem antes e após o condicionamento sobre a qualidade fisiológica de sementes de mamão. As sementes foram condicionadas em soluções de PEG6000 a -0,1 MPa, -1,0 MPa e em água destilada com dois níveis de $\mathrm{GA}_{3}, 0$ ou 200 mg.L-1 . Para cada solução osmótica ou água destilada, utilizou-se o delineamento estatístico inteiramente casualizado, com quatro repetições, em esquema fatorial $3 \times 2+2$, sendo três combinações de condicionamento e secagem: 1 . sementes condicionadas logo depois de retiradas do fruto com $67,0 \%$ de teor de água; 2. sementes secas até $11,5 \%$ e condicionadas; e 3. sementes secas, condicionadas e secas novamente $\mathrm{x}$ dois níveis de $\mathrm{GA}_{3}\left(0\right.$ e $\left.200 \mathrm{mg} . \mathrm{L}^{-1}\right)+$ dois tratamentos adicionais sem condicionamento, um com sementes úmidas $(67 \%)$ e o outro com sementes secas $(11,5 \%)$. Avaliou-se o teor de água (\%), a germinação (\%) aos 14, 21 e 28 dias, a condutividade elétrica $(\mu \mathrm{s} / \mathrm{cm} / \mathrm{g})$, massa seca de plântulas (g) e o comprimento de plântulas $(\mathrm{mm})$. Nas soluções com menor potencial osmótico, a presença de giberelina na solução de condicionamento aumentou a germinação. A secagem das sementes após o condicionamento ocasionou redução na qualidade fisiológica das mesmas, independente da presença ou ausência de giberelina na solução.
\end{abstract}

Termos para indexação: germinação, condicionamento, reguladores de crescimento, mamão.

\section{EFFECTS OF GIBBERELLIC ACID AND DRYING IN OSMOTIC CONDITIONING ON VIABILITY AND VIGOR OF PAPAYA (Carica papaya L.) SEEDS}

\begin{abstract}
The objective of this study was to evaluate the effects of the presence or absence of gibberellic acid in the conditioning solution and drying, before and after osmotic conditioning, on papaya seed viability and vigor. The seeds were placed in solutions of PEG-6000 at $-0.1 \mathrm{MPa},-1.0 \mathrm{MPa}$ and in distilled water with two levels of $\mathrm{GA}_{3}, 0$ or $200 \mathrm{mg} . \mathrm{L}^{-1}$. A completely randomized experimental design with four replications in a $3 \times 2+2$ factorial design was employed with three combinations of conditioning and drying: 1 . Seeds conditioned after extracted from fruit, with $67.0 \%$ moisture content; 2. Dry seeds (11.5\%) and conditioned; and 3. Dry seeds conditioned and redried to $11.5 \%$, with two levels of $\mathrm{GA}_{3}\left(0\right.$ and $\left.200 \mathrm{mg} . \mathrm{L}^{-1}\right)$. Two additional treatments, both without conditioning, one using seeds with $67 \%$ moisture content and another with dry seeds with $11.5 \%$ moisture content were also tested. Moisture content (\%), germination at 14, 21 and 28 days (\%), electrical conductivity
\end{abstract}

${ }^{1}$ Submetido em 17/10/2007. Aceito para publicação em 17/01/2008.

${ }^{2}$ Professor do Departamento de Fitotecnia Universidade Federal Rural do Rio de Janeiro - Instituto de Agronomia - Departamento de Fitotecnia. 23890-000, Seropédica, RJ, higino@ufrrj.br;
${ }^{3}$ Doutorando em Fitotecnia e Professor Substituto na Universidade Federal Rural do Rio de Janeiro - Instituto de Agronomia - Departamento de Fitotecnia.sousacm@yahoo.com.br; 
$(\mu \mathrm{s} / \mathrm{cm} / \mathrm{g})$, seedling dry weight $(\mathrm{g})$ and seedling length $(\mathrm{mm})$ were evaluated. The seeds conditioned in lower osmotic potential solution and in the presence of gibberellic acid improved the papaya seed germination. Drying the conditioned seeds decreased the seed vigor and the viability, regardless of presence or absence of gibberellic acid.

Index terms: germination, conditioning, plant growth regulator, papaya.

\section{INTRODUÇÃO}

O cultivo do mamoeiro (Carica papaya L.) geralmente é conduzido com alta densidade e a cada três anos torna-se necessária a renovação das plantas, o que gera a demanda da produção de mudas e, conseqüentemente de sementes, uma vez que é a forma predominante de propagação da espécie, razão pela qual se torna importante conhecer as qualidades físicas, fisiológicas, genéticas e sanitárias das sementes para obter mudas com excelente qualidade e vigor no momento da implantação da cultura no campo (Ruggiero, 1988).

Existem muitas controvérsias quanto à germinação das sementes de mamão. Para Singh \& Singh (1981) e Santos et al. (1999), as sementes de mamão recém-colhidas apresentam germinação máxima, já Yahiro \& Oryoji (1980) e Viggiano et al. (2000) relataram que as sementes recémcolhidas de mamão apresentam baixa germinação, devido, provavelmente, a uma dormência pós-colheita. Isto foi confirmado por Aroucha (2004) em sementes de mamão da cv Golden e híbrido 'Tainung 01' que independente do estádio de maturação dos frutos observou baixa germinação inicial, sendo necessário um período de armazenamento das sementes de 8 a 16 meses para que as mesmas apresentassem mais de $80 \%$ de germinação. Estes fatos podem estar associados com o balanço hormonal endógeno nos tecidos, uma vez que sementes em desenvolvimento ou recém formadas podem apresentar altos níveis de $\mathrm{ABA}$ e baixos teores de giberelinas, sendo que estes dois hormônios, nestas condições, influenciam diretamente no processo de germinação.

Após a extração é recomendável que as sementes de mamão sejam lavadas em água corrente para a eliminar fragmentos de polpa, tecidos placentários e para a retirada da sarcotesta, pois a sua presença pode resultar em germinação lenta e desuniforme (Schmildt et al, 1993). No entanto, Manica (1982) e Gherardi \& Valio (1976) afirmam que substâncias inibidoras de crescimento podem estar presentes tanto na sarcotesta quanto na esclerotesta. Embora tais substâncias inibidoras não sejam totalmente identificadas, pelos pesquisadores, atribui-se a essas a regulação da germinação.

$\mathrm{O}$ uso de reguladores de crescimento na fase de germinação, em alguns casos melhora o desenvolvimento das plântulas, acelerando a velocidade de emergência e realçando o potencial das sementes de várias espécies. Segundo Khan et al. (1978), o uso de compostos químicos biologicamente ativos, como reguladores de crescimento, pode cessar ou diminuir o impacto de fatores adversos durante o processo de germinação das sementes. $\mathrm{O}$ uso de giberelina na fase de germinação pode melhorar o vigor e a germinação de sementes de várias espécies, principalmente sob condições adversas (Bevilaqua et al., 1993; Cunha \& Casali, 1989).

Um dos sintomas mais importantes do declínio da qualidade fisiológica de sementes é o aumento do intervalo da germinação da primeira e da última semente, ou seja, a desuniformidade de emergência entre plântulas de um mesmo lote (Eira \& Marcos-Filho, 1990). Desse modo, a utilização de técnicas que possam acelerar e conseqüentemente trazer uniformidade da germinação das sementes, poderá trazer grandes benefícios para os produtores de mudas.

Diversos tratamentos têm sido utilizados para superar problemas de baixa germinação e desuniformidade na emergência de plântulas de mamão, entre estes a fermentação, a imersão de sementes em soluções de Hipoclorito de Sódio, $\mathrm{KNO}_{3}$ ou $\mathrm{GA}_{3}$, o envelhecimento acelerado e o condicionamento osmótico (Viggiano, 2000 e Aroucha, 2004).

O condicionamento osmótico ou "priming" tem sido usado para melhorar o desempenho de sementes de espécies ornamentais e agrícolas, por acelerar o processo germinativo e uniformizar a germinação (Khan, 1992, Yoon et al., 1997 e Bradford, 1986). O priming também auxilia as sementes a superar estresses ambientais, como as altas e as baixas temperaturas e estresse hídrico e salino (Yoon et al., 1997).

De acordo com Bradford (1986), para se obterem condições favoráveis ao condicionamento osmótico são importantes a temperatura, a concentração da solução ou potencial osmótico, o período de duração do tratamento, o método e o período de secagem após o tratamento. Outros fatores que afetam o sucesso do condicionamento osmótico 
são: a espécie, a cultivar e, dentro da mesma cultivar, o vigor dos lotes de sementes. Fessel et al. (2001), trabalhando com sementes de alface confirmaram as informações de Bradford (1986) e ainda verificaram que a resposta das sementes ao condicionamento osmótico variou em função do cultivar, do nível de vigor das sementes e do período de embebição das sementes na solução osmótica.

Aroucha et al. (2003) concluíram que o condicionamento osmótico com sementes de mamão em 200 ppm GA 3 por 7, 14 e 21 dias melhorou a germinação, embora Medeiros et al (2000) tenham relatado que o tratamento das sementes de mamoeiro com 100 ppm de $\mathrm{GA}_{3}$ e água destilada não influenciou na germinação.

As sementes de mamão toleram a dessecação até teores de 4,5\% de água sem perda de viabilidade. Os trabalhos com secagem têm sido realizados sob temperatura ambiente e complementados com temperaturas entre 25 e $30^{\circ} \mathrm{C}$ e umidade relativa do ar até $15 \%$ (Althoff \& Carmona, 1999). Portanto, o conhecimento do processo de secagem e de embebição de sementes nestes métodos é importante para se determinar o período adequado de condicionamento das sementes.

Os objetivos deste trabalho foram avaliar os efeitos da secagem, antes e após o condicionamento osmótico, e da presença ou ausência de giberelina na solução de condicionamento sobre qualidade fisiológica de sementes de mamão.

\section{MATERIAL E MÉTODOS}

O presente trabalho foi realizado no Laboratório de Controle de Qualidade de Sementes do Departamento de Fitotecnia da Universidade Federal Rural do Rio de Janeiro, em Seropédica-RJ. Os frutos de mamão do tipo "solo" pesando entre 356 a $470 \mathrm{~g}$, no estádio de maturação caracterizada por apresentarem entre 50 a $75 \%$ da superfície com coloração amarela, foram mantidos em recipiente fechado até esta coloração se completar uniformemente por todo o fruto. As sementes foram extraídas manualmente, lavadas em água corrente para a eliminar a polpa e tecidos placentários e ainda foram friccionadas para retirada da sarcotesta. Em seguida foram colocadas sobre papel toalha para retirar excesso de água. Obteve-se em média 480 sementes por fruto. Amostras destas sementes foram retiradas para a determinação do teor de água utilizando o método de estufa a $105 \pm 3^{\circ} \mathrm{C}$ por 24 horas (Brasil, 1992) e os resultados foram expressos em porcentagem na base úmida.

Primeiro ensaio - Curva de secagem: As sementes foram mantidas em temperatura e umidade relativa do ambiente, até atingirem 18,3\% de teor de água. Em seguida as sementes foram mantidas em um recipiente contendo sílica gel com $40 \%$ de umidade relativa do ar a $30^{\circ} \mathrm{C}$. O teor de água nas sementes foi determinado nos períodos de $1,2,3,18,46$, $62,86,110,134$ horas, períodos suficientes para ocorrer a estabilização do teor de água nas sementes, cerca de $11,5 \%$. Diante destes resultados, determinou a curva de secagem.

Segundo ensaio - Condicionamento osmótico: Neste ensaio as sementes foram imersas em água destilada e soluções de Polietileno glicol - PEG6000 com dois níveis de potencial osmótico, -0,1 MPa e -1,0 MPa. As concentrações foram obtidas segundo Villela et al. (1991). As sementes permaneceram nas soluções utilizadas no condicionamento durante 24 horas sob agitação constante de $150 \mathrm{rpm}$ a $15^{\circ} \mathrm{C}$. Em cada nível de potencial osmótico foi realizado um experimento composto de três condições de condicionamento e secagem das sementes. 1.sementes recém-extraídas do fruto com $67 \%$ de teor de água e condicionadas (SUC); 2. sementes secas a $11,5 \%$ de teor de água e condicionadas (SSC); 3. sementes secas (11,5\%), condicionadas e secas novamente $(11,5 \%)$ (SSCS). Estes três tratamentos foram associados a dois níveis de giberelina - $\mathrm{GA}_{3}\left(0\right.$ ou $\left.200 \mathrm{mg} . \mathrm{L}^{-1}\right)$ na solução de condicionamento. Além destas combinações foram utilizados dois tratamentos adicionais, ambos sem condicionamento, um com sementes úmidas (67\%) (SU) e o outro com sementes secas $(11,5 \%)$ (SS). As avaliações realizadas antes e após os tratamentos foram:

Teor de água - determinou-se o teor de água nas sementes, por meio de pesagens, após 1, 2, 4, 8, 12 e 24 horas do início do condicionamento e embebição.

Teste de germinação - foram utilizadas 50 sementes sobre papel umedecido comágua destilada na proporção de 2,5 vezes o peso do papel e colocadas em germinador em temperatura alternada de $20 / 30^{\circ} \mathrm{C}$ por 16 horas de luz e 8 horas de escuro, (Brasil, 1992). As avaliações foram realizadas aos 14, 21 e 28 dias após o inicio do teste, considerando as plântulas normais com comprimento igual ou superior a $3,0 \mathrm{~cm}$ e os resultados expressos em porcentagem. A primeira avaliação ocorreu após verificar o início da germinação das sementes.

Comprimento de plântulas - foram distribuídas 20 sementes alinhadas em duas fileiras entre folhas de papel umedecidas com água destilada na proporção de 2,5 vezes o peso do papel e colocadas em germinador com as mesmas condições utilizadas no teste de germinação. O comprimento 
das plântulas foi obtido aos 21 dias após o início do teste, medindo o comprimento do hipocótilo das plântulas normais a partir de 3,0 cm e os resultados foram expressos em $\mathrm{cm}$.

Massa seca de plântula - foram utilizadas as plântulas normais obtidas no teste do comprimento de plântula as quais foram acondicionadas em sacos de papel, secas em estufa com circulação de ar a $80^{\circ} \mathrm{C}$ por 24 horas e posteriormente determinou a massa seca, expressando o resultado em mg/plântula.

Condutividade elétrica - amostras de 50 sementes foram pesadas e imersas em $75 \mathrm{ml}$ de água destilada e mantidas a $25^{\circ} \mathrm{C}$ por 24 horas. Após este período foi realizada a leitura da condutividade elétrica com o auxílio de um condutivímetro e os resultados foram expressos em $\mu \mathrm{S} /$ cm.g-1 (Vieira \& Krzyzanowski, 1999). Os resultados obtidos foram submetidos à análise de variância considerando o delineamento estatístico inteiramente casualizado com quatro repetições. A análise dos efeitos do condicionamento foi realizada para cada solução de condicionamento: Água destilada, solução de PEG - 0,1 MPa e solução de PEG - 1,0 $\mathrm{MPa}$. Considerou-se o fatorial $3 \times 2+2$, sendo: três condições de secagem das sementes $\mathrm{x}$ presença e ausência de giberelina $\left(\mathrm{GA}_{3}\right)+$ os tratamentos controle sem o condicionamento.

\section{RESULTADOS E DISCUSSÃO}

\section{Curvas de secagem e de embebição}

Na Figura 1 encontram-se os teores de água das sementes de mamão mantidas em diferentes soluções utilizadas no condicionamento, e na Figura 2, a variação do teor de água nas sementes em função do período de secagem. Observa-se que, independente da solução utilizada, o teor de água das sementes aumentou muito rápido inicialmente e se manteve constante a partir de aproximadamente 1 hora até 24 horas de embebição atingindo a média de $70 \%$ de teor de água nas soluções de PEG6000 a -0,1 MPa, $200 \mathrm{mg} \mathrm{L}^{-1}$ de $\mathrm{GA}_{3}$ e água destilada. Na solução com PEG6000 a -1,0 MPa, as sementes apresentaram $64 \%$ de teor de água. Em relação à secagem observa-se que a partir de 62 horas a variação do teor de água nas sementes não foi significativa e após este período as sementes apresentaram em média 11,5\% de teor de água.

\section{Efeitos do condicionamento osmótico}

Os resultados de germinação das sementes apresentaram ampla variação nos tratamentos estudados (Tabelas 1, 2 e 3). De uma maneira geral, com o aumento do potencial hídrico da solução de condicionamento, houve redução na taxa de germinação. Aos 14 dias somente não houve germinação das sementes condicionadas com -1,0 MPa (Tabela 1). Neste tratamento, aos 21 e 28 dias, apesar de ocorrer germinação, esta foi inferior aos tratamentos com condicionamento em água ou -0,1 MPa (Tabelas 2 e 3). A redução da taxa de germinação e da germinação final em função do aumento do potencial hídrico da solução utilizada no condicionamento pode estar associada com a disponibilidade e difusão do oxigênio na solução de embebição, visto que a absorção de água não foi limitante (Figura 1). As sementes condicionadas em água apresentaram maior germinação, provavelmente devido a maior disponibilidade de oxigênio durante o processo de condicionamento. De acordo com Trigo et al. (1999) sementes de cebola osmocondicionadas com soluções aeradas de $\mathrm{KNO}_{3}$ apresentam melhor desempenho em relação às condicionadas com PEG6000.
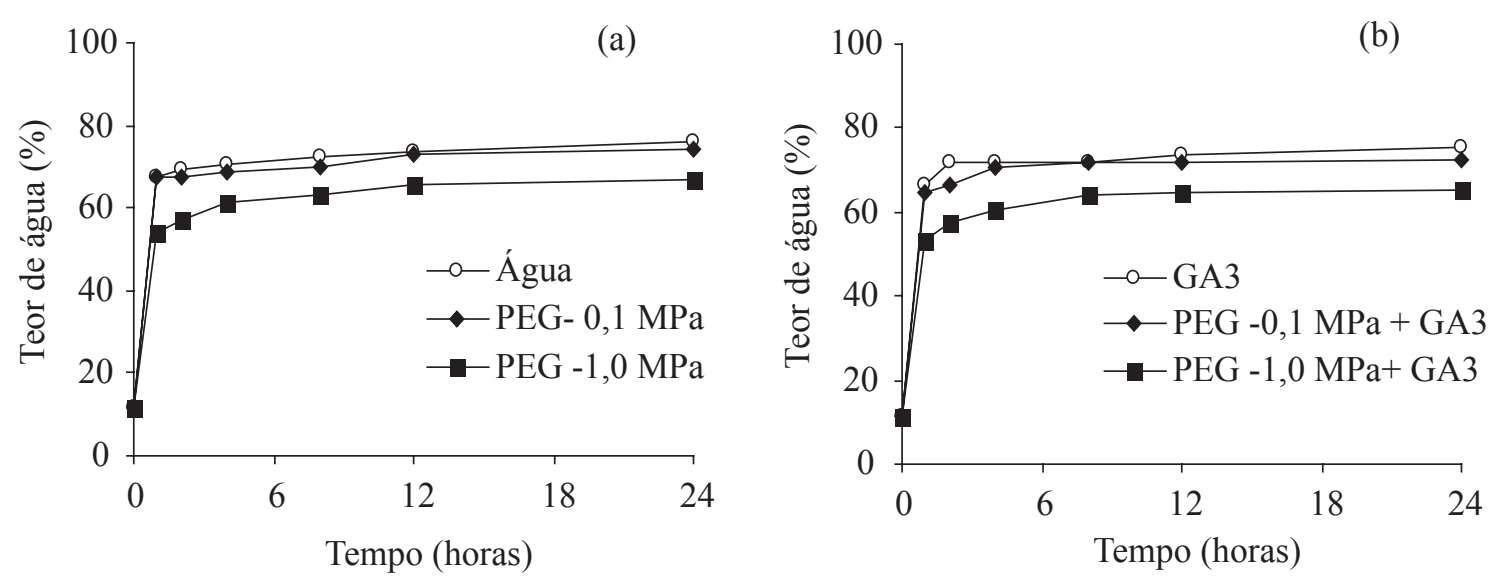

FIGURA 1. Teor de água (\%) em sementes de mamão mantidas durante 24 horas em diferentes soluções de condicionamento osmótico na ausência (a) ou presença (b) de giberelina, a $15^{\circ} \mathrm{C}$. 


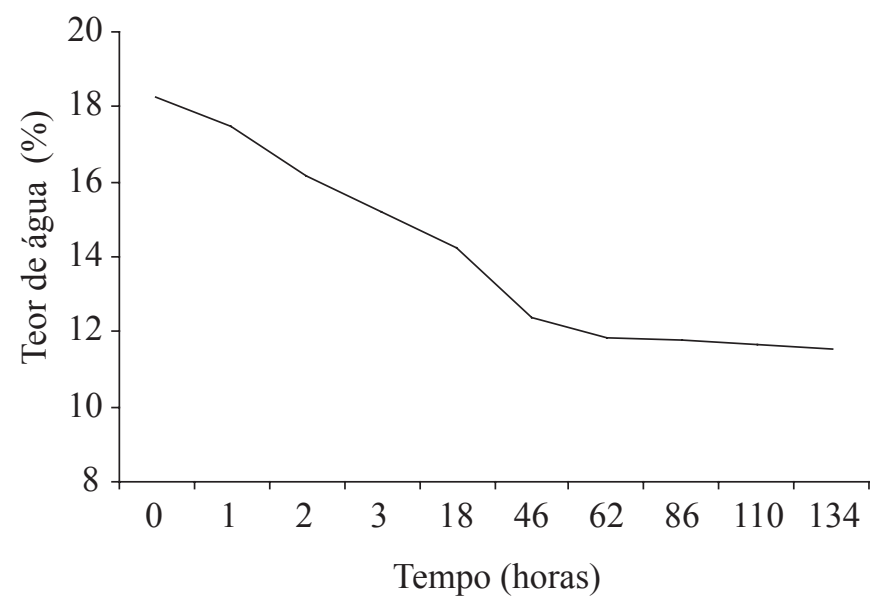

FIGURA 2. Teor de água de sementes de mamão após diferentes períodos de secagem.

A presença de giberelina na solução de condicionamento, independente do método de condicionamento e secagem das sementes, favoreceu a germinação. Entretanto, a associação de $\mathrm{GA}_{3}$ com PEG6000 na solução de condicionamento reduziu a germinação de sementes de mamão (Tabelas 1 e 2), o mesmo ocorrendo para a secagem das sementes, principalmente após o condicionamento. O PEG6000 reduziu o efeito do $\mathrm{GA}_{3}$ como promotor da germinação, principalmente em sementes condicionadas a $-1,0 \mathrm{MPa}$.

Lopes e Balbinot (2006) constataram que o condicionamento de sementes de cenoura por imersão em soluções aeradas seguidas de secagem não afetou a germinação e o vigor destas sementes.
$\mathrm{Na}$ avaliação aos 28 dias (Tabela 3), o resultado da germinação das sementes apresentou a mesma tendência das avaliações anteriores. Comparando os três tratamentos de condicionamento e a presença de $\mathrm{GA}_{3}$ nas soluções, verifica-se que nas sementes que foram submetidas aos tratamentos de secagem, condicionadas e secas novamente, a taxa de germinação foi inferior àquelas que foram secas e posteriormente condicionadas, independente das soluções utilizadas. De acordo com Aroucha (2004) e Viggiano (2000) sementes de mamão recém extraídas dos frutos apresentam baixa germinação inicial. Os resultados do presente trabalho confirmam este comportamento visto que, as sementes úmidas e secas, ambas sem condicionamento, apresentaram taxa de germinação praticamente nula, demonstrando que o condicionamento, independente da forma adotada, incrementou a taxa de germinação e a germinação final.

Aos 28 dias, as sementes que foram submetidas ao condicionamento na solução de PEG -1,0 MPa, e secas posteriormente, mesmo com a presença de $\mathrm{GA}_{3}$, não germinaram, enquanto isso não foi observado quando utilizou PEG a -0,1 MPa e água (Tabela 3).

As sementes secas e condicionadas em solução de PEG a -0,1 MPa com $\mathrm{GA}_{3}$ presente, apresentaram maior germinação, significativamente superior às demais. Já na ausência de $\mathrm{GA}_{3}$ a germinação praticamente não ocorreu. Na solução de PEG -1,0 MPa mesmo com a presença de $\mathrm{GA}_{3}$ não houve germinação das sementes que foram submetidas ao processo de secagem, apenas nas sementes úmidas condicionadas houve germinação, no entanto, com valor inferior àquele

TABELA 1. Médias de germinação (\%) de sementes de mamão, aos 14 dias, submetidas ao condicionamento osmótico, com ou sem a presença de giberelina na solução e com ou sem secagem das sementes.

\begin{tabular}{lcccccc}
\hline & \multicolumn{2}{c}{ Água } & \multicolumn{2}{c}{ PEG 6000 -0,1 MPa } & \multicolumn{2}{c}{ PEG 6000 -1,0 MPa } \\
\cline { 2 - 7 } & \multicolumn{7}{c}{200} & 0 & 200 & 0 & 200 & 0 \\
\cline { 2 - 7 } & $71,5 \mathrm{~A}^{*}$ & $4,0 \mathrm{~B}$ & $4,5 \mathrm{~B}$ & $3,00 \mathrm{C}$ & $6,5 \mathrm{~A}$ & $0,00 \mathrm{~B}$ \\
SUC & $62,0 \mathrm{~B}$ & $22,0 \mathrm{C}$ & $53,5 \mathrm{~A}$ & $0,00 \mathrm{C}$ & $0,00 \mathrm{~B}$ & $0,00 \mathrm{~B}$ \\
$\mathrm{SSC}$ & $37,5 \mathrm{C}$ & $0,00 \mathrm{D}$ & $48,0 \mathrm{~A}$ & $0,00 \mathrm{C}$ & $0,00 \mathrm{~B}$ & $0,00 \mathrm{~B}$ \\
SSCS & & &
\end{tabular}

SU (67\%)

$0,00 \mathrm{D}$

$0,00 \mathrm{C}$

$0,00 \mathrm{~B}$

SS $(11,5 \%)$

$0,00 \mathrm{D}$

0,00 C

$0,00 \mathrm{~B}$

$\mathrm{CV}(\%) \quad 5,4 \quad 9,6 \quad 11,4$

Médias seguidas de mesma letra nas combinações dos níveis de giberelina com os tratamentos de condicionamento não diferenciam entre si pelo teste de Tukey ao nível de $5 \%$ de probabilidade de erro. 
TABELA 2. Médias de germinação (\%) de sementes de mamão, aos 21 dias, submetidas ao condicionamento osmótico, com ou sem a presença de giberelina na solução e com ou sem secagem das sementes.

\begin{tabular}{|c|c|c|c|c|c|c|}
\hline & \multicolumn{2}{|c|}{ Água } & \multicolumn{2}{|c|}{ PEG $6000-0,1 \mathrm{MPa}$} & \multicolumn{2}{|c|}{ PEG 6000 -1,0 MPa } \\
\hline & \multicolumn{6}{|c|}{ Concentrações de $\mathrm{GA}_{3}\left(\mathrm{mg} \mathrm{L}^{-1}\right)$} \\
\hline & 200 & 0 & 200 & 0 & 200 & 0 \\
\hline SUC & $78,00 \mathrm{~A}^{*}$ & $60,00 \mathrm{~B}$ & $49,00 \mathrm{C}$ & $40,50 \mathrm{D}$ & $42,00 \mathrm{~A}$ & $4,00 \mathrm{C}$ \\
\hline $\mathrm{SSC}$ & $75,80 \mathrm{~A}$ & $33,00 \mathrm{C}$ & $82,50 \mathrm{~A}$ & $3,00 \mathrm{E}$ & $0,00 \mathrm{C}$ & $19,25 \mathrm{~B}$ \\
\hline SSCS0 & $39,00 \mathrm{C}$ & $0,00 \mathrm{D}$ & $70,00 \mathrm{~B}$ & $0,00 \mathrm{E}$ & $0,00 \mathrm{C}$ & $0,00 \mathrm{C}$ \\
\hline SU (67\%) & \multicolumn{2}{|c|}{$0,00 \mathrm{D}$} & \multicolumn{2}{|c|}{$0,00 \mathrm{E}$} & \multicolumn{2}{|c|}{$0,00 \mathrm{C}$} \\
\hline SS $(11,5 \%)$ & \multicolumn{2}{|c|}{$0,00 \mathrm{D}$} & \multicolumn{2}{|c|}{$0,00 \mathrm{E}$} & \multicolumn{2}{|c|}{$0,00 \mathrm{C}$} \\
\hline CV (\%) & \multicolumn{2}{|c|}{8,8} & \multicolumn{2}{|c|}{10,1} & \multicolumn{2}{|c|}{17,6} \\
\hline
\end{tabular}

*médias seguidas de mesma letra nas combinações dos níveis de giberelina com os tratamentos de condicionamento não diferenciam entre si pelo teste de Tukey ao nível de $5 \%$ de probabilidade de erro.

TABELA 3. Médias de germinação (\%) de sementes de mamão, aos 28 dias, submetidas ao condicionamento osmótico, com ou sem a presença de giberelina na solução e com ou sem secagem das sementes.

\begin{tabular}{|c|c|c|c|c|c|c|}
\hline & \multicolumn{2}{|c|}{ Água } & \multicolumn{2}{|c|}{ PEG $6000-0,1 \mathrm{MPa}$} & \multicolumn{2}{|c|}{ PEG 6000 -1,0 MPa } \\
\hline & \multicolumn{6}{|c|}{ Concentrações de $\mathrm{GA}_{3}\left(\mathrm{mg} \mathrm{L}^{-1}\right)$} \\
\hline & 200 & 0 & 200 & 0 & 200 & 0 \\
\hline SUC & $80,50 \mathrm{~A}^{*}$ & $64,25 \mathrm{~B}$ & $58,00 \mathrm{C}$ & $46,25 \mathrm{D}$ & $42,00 \mathrm{~A}$ & $4,00 \mathrm{C}$ \\
\hline $\mathrm{SSC}$ & $78,50 \mathrm{~A}$ & $41,00 \mathrm{C}$ & $89,75 \mathrm{~A}$ & $4,00 \mathrm{E}$ & $0,00 \mathrm{C}$ & $21,50 \mathrm{~B}$ \\
\hline SSCS & $39,00 \mathrm{C}$ & $7,00 \mathrm{D}$ & $75,00 \mathrm{~B}$ & $1,00 \mathrm{E}$ & $0,00 \mathrm{C}$ & $0,00 \mathrm{C}$ \\
\hline SU $(67 \%)$ & \multicolumn{2}{|c|}{$0,00 \mathrm{D}$} & \multicolumn{2}{|c|}{$0,00 \mathrm{E}$} & \multicolumn{2}{|c|}{$0,00 \mathrm{C}$} \\
\hline SS $(11,5 \%)$ & \multicolumn{2}{|c|}{$1,00 \mathrm{D}$} & \multicolumn{2}{|c|}{$1,00 \mathrm{E}$} & \multicolumn{2}{|c|}{$1,00 \mathrm{C}$} \\
\hline CV (\%) & \multicolumn{2}{|c|}{9,9} & \multicolumn{2}{|c|}{11,9} & \multicolumn{2}{|c|}{22,9} \\
\hline
\end{tabular}

* médias seguidas de mesma letra nas combinações dos níveis de giberelina com os tratamentos de condicionamento não diferenciam entre si pelo teste de Tukey ao nível de $5 \%$ de probabilidade de erro.

observado, nas sementes submetidas as demais soluções utilizadas para o condicionamento.

Em relação à massa seca das plântulas (Tabela 4), verifica-se a mesma tendência dos efeitos dos tratamentos sobre a germinação, uma vez que não houve uma variação muito ampla quanto ao acúmulo de massa. As sementes recém extraídas dos frutos, cujo teor de água era $67 \%$, não germinaram, não sendo possível desta forma, realizar as avaliações que utilizavam as plântulas. No entanto, as plântulas obtidas de sementes que foram secas, sem condicionamento, foram semelhantes aos melhores tratamentos (Tabela 4). Apesar de a giberelina favorecer a expansão celular e elogamento de caule (Davies, 1995), este efeito não foi observado nas plântulas, provavelmente, porque o uso de giberelina na germinação não interfere posteriormente no crescimento das plântulas.

As sementes condicionadas em água apresentaram comprimento de plântulas inferior àquelas condicionadas em PEG6000 a -0,1 e -1,0 MPa (Tabela 5).

Os valores de condutividade elétrica foram maiores nas sementes após o condicionamento a -1,0 MPa e nas sementes úmidas ou secas, ambas sem condicionamento (Tabela 6). Durante o condicionamento pode ocorrer liberação de solutos para o meio, ocasionando redução na condutividade. Na solução de PEG -1,0 MPa observou maior condutividade elétrica, provavelmente devido a menor liberação de solutos durante o processo. Estes resultados sugerem que o teste de condutividade poderia ser utilizado com o objetivo de avaliar rapidamente os efeitos do condicionamento e selecionar metodologias mais adequadas utilizando sementes de mamão.

As vantagens e benefícios do condicionamento de sementes são amplamente divulgados (Bradford, 1986; Khan, 1992, McDonald, 1998), entretanto, os resultados desta 
TABELA 4. Médias de massa seca de plântulas (g) de mamão obtidas de sementes submetidas ao condicionamento osmótico, com ou sem a presença de giberelina na solução e com ou sem secagem das sementes.

\begin{tabular}{|c|c|c|c|c|}
\hline & \multicolumn{2}{|c|}{ Água } & \multicolumn{2}{|c|}{ PEG 6000 -0,1 MPa } \\
\hline & \multicolumn{4}{|c|}{ Concentrações de $\mathrm{GA}_{3}\left(\mathrm{mg} \mathrm{L}^{-1}\right)$} \\
\hline & 200 & 0 & 200 & 0 \\
\hline SUC & $0,0041 \mathrm{~A}^{*}$ & $0,0041 \mathrm{~A}$ & $0,0021 \mathrm{C}$ & $0,0040 \mathrm{~B}$ \\
\hline $\mathrm{SSC}$ & $0,0046 \mathrm{~A}$ & $0,0045 \mathrm{~A}$ & $0,0051 \mathrm{~A}$ & $0,0042 \mathrm{AB}$ \\
\hline SSCS & $0,0041 \mathrm{~A}$ & $0,0038 \mathrm{~A}$ & $0,0043 \mathrm{AB}$ & \\
\hline SU (67\%) & \multicolumn{2}{|c|}{$0,0000 \mathrm{~B}$} & \multicolumn{2}{|c|}{$0,000 \mathrm{D}$} \\
\hline SS $(11,5 \%)$ & \multicolumn{2}{|c|}{$0,0037 \mathrm{~A}$} & \multicolumn{2}{|c|}{$0,0035 \mathrm{~B}$} \\
\hline \multirow[t]{4}{*}{$\mathrm{CV}(\%)$} & \multicolumn{2}{|c|}{12,1} & \multicolumn{2}{|c|}{12,6} \\
\hline & \multicolumn{2}{|c|}{ Água } & \multicolumn{2}{|c|}{ PEG $6000-0,1 \mathrm{MPa}$} \\
\hline & \multicolumn{4}{|c|}{ Concentrações de $\mathrm{GA}_{3}\left(\mathrm{mg} \mathrm{L}^{-1}\right)$} \\
\hline & 200 & 0 & 200 & 0 \\
\hline SUC & $0,0041 \mathrm{~A}^{*}$ & $0,0041 \mathrm{~A}$ & $0,0021 \mathrm{C}$ & $0,0040 \mathrm{~B}$ \\
\hline $\mathrm{SSC}$ & $0,0046 \mathrm{~A}$ & $0,0045 \mathrm{~A}$ & $0,0051 \mathrm{~A}$ & $0,0042 \mathrm{AB}$ \\
\hline SSCS & $0,0041 \mathrm{~A}$ & $0,0038 \mathrm{~A}$ & $0,0043 \mathrm{AB}$ & $0,0035 \mathrm{~B}$ \\
\hline SU (67\%) & \multicolumn{2}{|c|}{$0,0000 \mathrm{~B}$} & \multicolumn{2}{|c|}{$0,000 \mathrm{D}$} \\
\hline $\mathrm{SS}(11,5 \%)$ & \multicolumn{2}{|c|}{$0,0037 \mathrm{~A}$} & \multicolumn{2}{|c|}{$0,0035 \mathrm{~B}$} \\
\hline CV (\%) & \multicolumn{2}{|c|}{12,1} & \multicolumn{2}{|c|}{12,6} \\
\hline
\end{tabular}

* médias seguidas de mesma letra nas combinações dos níveis de giberelina com os tratamentos de condicionamento não diferenciam entre si pelo teste de Tukey ao nível de $5 \%$ de probabilidade de erro.

TABELA 5. Médias do comprimento de plântulas (cm) obtidas de sementes de mamão submetidas ao condicionamento osmótico, com ou sem a presença de giberelina na solução e com ou sem secagem das sementes.

\begin{tabular}{|c|c|c|c|c|c|c|}
\hline & \multicolumn{2}{|c|}{ Água } & \multicolumn{2}{|c|}{ PEG $6000-0,1 \mathrm{MPa}$} & \multicolumn{2}{|c|}{ PEG $6000-1,0 \mathrm{MPa}$} \\
\hline & \multicolumn{6}{|c|}{ Concentrações de $\mathrm{GA}_{3}\left(\mathrm{mg} \mathrm{L}^{-1}\right)$} \\
\hline & 200 & 0 & 200 & 0 & 200 & 0 \\
\hline SUC & $5,39 \mathrm{C}$ & $3,83 \mathrm{C}$ & $3,70 \mathrm{C}$ & $4,44 \mathrm{C}$ & $3,62 \mathrm{~B}$ & $0,00 \mathrm{C}$ \\
\hline $\mathrm{SSC}$ & $5,07 \mathrm{C}$ & $4,07 \mathrm{C}$ & $11,20 \mathrm{AB}$ & $9,70 \mathrm{~B}$ & $0,00 \mathrm{C}$ & $0,00 \mathrm{C}$ \\
\hline SSCS & $11,85 \mathrm{AB}$ & $11,10 \mathrm{~B}$ & $10,75 \mathrm{~B}$ & $11,10 \mathrm{AB}$ & $0,00 \mathrm{C}$ & $0,00 \mathrm{C}$ \\
\hline SU (67\%) & \multicolumn{2}{|c|}{$0,00 \mathrm{D}$} & \multicolumn{2}{|c|}{$0,00 \mathrm{D}$} & \multicolumn{2}{|c|}{$0,00 \mathrm{C}$} \\
\hline SS $(11,5 \%)$ & \multicolumn{2}{|c|}{$12,90 \mathrm{~A}$} & \multicolumn{2}{|c|}{$12,90 \mathrm{~A}$} & \multicolumn{2}{|c|}{$12,45 \mathrm{~A}$} \\
\hline $\mathrm{CV}(\%)$ & \multicolumn{2}{|c|}{11,2} & \multicolumn{2}{|c|}{9,9} & \multicolumn{2}{|c|}{43,9} \\
\hline
\end{tabular}

* médias seguidas de mesma letra nas combinações dos níveis de giberelina com os tratamentos de condicionamento não diferenciam entre si pelo teste de Tukey ao nível de $5 \%$ de probabilidade de erro.

pesquisa mostraram que há a necessidade de realizar ajustes na metodologia empregada, principalmente em relação a diferenças entre lotes de sementes, aeração da solução e interações com substâncias reguladoras de crescimento. 
TABELA 6. Médias de condutividade elétrica $\left(\mu \mathrm{S} / \mathrm{cm} \mathrm{g}^{-1}\right)$ de sementes de mamão submetidas ao condicionamento osmótico, com ou sem a presença de giberelina na solução e com ou sem secagem das sementes.

\begin{tabular}{|c|c|c|c|c|c|c|}
\hline & \multicolumn{2}{|c|}{ Água } & \multicolumn{2}{|c|}{ PEG $6000-0,1 \mathrm{MPa}$} & \multicolumn{2}{|c|}{ PEG $6000-1,0 \mathrm{MPa}$} \\
\hline & \multicolumn{6}{|c|}{ Concentrações de $\mathrm{GA}_{3}\left(\mathrm{mg} \mathrm{L}^{-1}\right)$} \\
\hline & 200 & 0 & 200 & 0 & 200 & 0 \\
\hline SUC & $17,69 \mathrm{~B}$ & $19,50 \mathrm{~B}$ & $19,07 \mathrm{C}$ & $19,47 \mathrm{C}$ & $61,89 \mathrm{DE}$ & $51,42 \mathrm{E}$ \\
\hline SSC & $9,83 \mathrm{D}$ & $8,95 \mathrm{D}$ & $10,27 \mathrm{D}$ & $8,52 \mathrm{D}$ & $90,34 \mathrm{AB}$ & $79,88 \mathrm{ABC}$ \\
\hline SSCS & $18,58 \mathrm{~B}$ & $15,16 \mathrm{C}$ & $17,62 \mathrm{D}$ & $23,03 \mathrm{~B}$ & $84,24 \mathrm{ABC}$ & $92,62 \mathrm{~A}$ \\
\hline SU (67\%) & \multicolumn{2}{|c|}{$73,07 \mathrm{~A}$} & \multicolumn{2}{|c|}{$73,07 \mathrm{~A}$} & \multicolumn{2}{|c|}{ 73,07CD } \\
\hline SS $(11,5 \%)$ & \multicolumn{2}{|c|}{$74,64 \mathrm{~A}$} & \multicolumn{2}{|c|}{$74,64 \mathrm{~A}$} & \multicolumn{2}{|c|}{$74,64 \mathrm{BCD}$} \\
\hline CV (\%) & \multicolumn{2}{|c|}{3,5} & \multicolumn{2}{|c|}{3,3} & \multicolumn{2}{|c|}{9,6} \\
\hline
\end{tabular}

médias seguidas de mesma letra nas combinações dos níveis de giberelina com os tratamentos de condicionamento não diferenciam entre si pelo teste de Tukey ao nível de $5 \%$ de probabilidade de erro.

\section{CONCLUSÕES}

O condicionamento em solução de PEG 6000 a - $0,1 \mathrm{MPa}$ ou em água, em presença de giberelina, é uma alternativa adequada para uniformizar e acelerar a germinação das sementes de mamão.

A secagem das sementes após o condicionamento osmótico ocasiona redução na sua qualidade fisiológica, independente da presença ou ausência de giberelina na solução.

\section{REFERÊNCIAS}

AROUCHA, E.M.M. Influência do estádio de maturação, da época de colheita e repouso dos frutos e do osmocondicionamento na qualidade fisiológica de sementes de mamão (Carica papaya L.). 2004. 122f. Tese (Doutorado em Produção Vegetal) - Universidade Estadual do Norte Fluminense Darcy Ribeiro, Campos dos Goytacazes.

AROUCHA, M.M.; SILVA, R.F.; VIEIRA, H.D.; TEIXEIRA, M.T.; AROUCHA, M.C.M.; VIANA, A.P. Efeitos da hidratação e do condicionamento osmótico na germinação das sementes de mamão. In: CONGRESSO BRASILEIRO DE SEMENTES, 13., 2003, Londrina. 2003. Anais... Londrina: Informativo Abrates, 2003, v.13, n.3, p.174.

ALTHOFF, M.A.; CARMONA,R. Conservação de sementes de mamão (Carica papaya L.- CARICACEAE). Revista Brasileira de Sementes, Londrina, v.21, n.1, p.151-156, 1999.

BRASIL. Ministério da Agricultura e Reforma Agrária. Regras para Análise de Sementes. Brasília: SNDA/DNPV/ CLAV, 1992. 365p.
BRADFORD, K.J. Manipulation of seed water relation via osmotic priming to improve germination under stress conditions. HortScience, Alexandria, v.21, n.3, p.1105-1112, 1986.

BEVILAQUA, G.A.P.; PESKE, S.T.; SANTOS-FILHO, B.G. Desempenho de sementes de arroz irrigado tratadas com regulador de crescimento. I. Efeito na emergência a campo. Revista Brasileira de Sementes, Brasília, v.15, n.1, p.75-80, 1993.

CUNHA, R.; CASALI, W.D. Efeito de substâncias reguladoras de crescimento sobre a germinação de sementes de alface (Lactuca sativa L.). Revista Brasileira de Fisiologia Vegetal, Brasília, v.1, n.2, p.121-132, 1989.

DAVIES, P.J. The plant hormones: their nature, occurrence, and functions. In: DAVIES, P.J. Plant hormones: physiology, biochemistry and molecular biology. (2Ed). Amsterdam: Kluwer Academic Publishers, 1995. p.1-12.

EIRA, M.T.S.;MARCOS-FILHO, J. Condicionamento osmótico de sementes de alface. I. Efeitos sobre a germinação. Revista Brasileira de Sementes, Brasília, v.12, n.1, p.9-27, 1990.

FESSEL，S.A.; VIEIRA， R.D.; RODRIGUES，T.J.D.; FAGIOLI, M.; PAULA, R.C. Eficiência do condicionamento osmótico em sementes de alface. Revista Brasileira de Sementes, Brasília, v.23, n.1, p. 128-133, 2001.

GHERARDI, E.; VALIO, I.F.M. Occurrence of promoting and inhibitory substances in the seed arils of Carica papaya L. Journal of Horticultural Science, v.51, p.1-4, 1976.

LOPES, H.M.; BALBINOT, E. Efeitos do condicionamento fisiológico e da secagem na germinação e no vigor de sementes de cenoura. Revista Brasileira de Sementes, Pelotas, v.28, n.1, p.1-8, 2006.

KHAN, A.A.; TAO, K.L.; KNYPL, J.S.; BORKOWSKA, B.; 
POWELL, L.E. Osmoticconditioning of seeds: physiological and biochemical changes. Acta Horticulturae, Wageningen, v.83, p. 267-283. 1978

KHAN, A.A. Preplant physiological seed conditioning. Horticultural Review, Edimburgh, v.13, p.131-181, 1992.

MEDEIROS, S.A.F.; FAGUNDES, G.R.; MACHADO FILHO, J.A.; YAMANISHI, O.K. Efeito do ácido giberélico na germinação e formação de mudas de mamoeiro (Carica papaya 1. cv. 'Sunrise Solo') em bandejas de poliestireno. In: Congresso Brasileiro de Fruticultura, 15, 2000, FortalezaCE. Anais... Fortaleza, SBF, 2000, CD ROM, 1CD.

MANICA, I. Fruticultura Tropical 3-mamão. São Paulo: Ceres, 1982, 255p.

McDONALD, M.B. Seed quality assessment. Seed Science Research, Wallingford, v.8, p.265-275, 1998.

RUGGIERO, D.; LEONEL, S. Mamão. Jaboticabal: Departamento de Horticultura FCAV-UNESP, 1988. 321p.

SCHMILDT, E.R., FRONZA, V., DIAS, J.L.S., Unëd, S.H., ALVARENGA, E.M. Comparação de métodos físicos de remoção da sarcotesta e de métodos de secagem de sementes de mamoeiro (Carica papaya L.). Revista Brasileira de Sementes, Brasília,_v.15, n.2, p.147-151, 1993.

SANTOS, R.C.A.; SAMPAIO, L.S.V; COSTA, J.A. Condição ambiental, teor de água e embalagem na viabilidade e no vigor de sementes de mamão. Revista Brasileira de Sementes, Brasília, v.21, n.2, p.194-202, 1999.
SINGH, R.M.; SINGH, I.D. Effect of methods and duration of storage on seed germination and seedling vigor in papaya. Seed Research, New Dehli, v.9, p.67-72, 1981.

TRIGO, M.F.O.O.; NEDEL, J.L.; TRIGO, L.F.N. Condicionamento osmótico em sementes de cebola: i. efeitos sobre a germinação. Scientia Agricola, Piracicaba, v.56, n.4, p.1059-1067, 1999.

VIEIRA, R. D.; KRZYZANOWSKI, F. C. Teste de Condutividade elétrica. In: KRZYZANOWSKI, F. C.; VIEIRA, R. D.; FRANÇA-NETO, J. B. (Ed.). Vigor de sementes: conceitos e testes. Londrina: ABRATES, cap.4. p.4-26, 1999.

VIGGIANO, J.R. SILVA, R.F. VIEIRA, H.D. Ocorrência de dormência em sementes de mamão (Carica papaya L.). Sementes Online, Pelotas, v.1, n.1, p.6-10, 2000.

VILELLA, F.A.; DONI FILHO, L.; SEQUEIRA, E.L. Tabela de potencial osmótico em função da concentração de polietileno glicol 6000 e da temperatura. Pesquisa Agropecuária Brasileira, Brasília, v. 26, n. 11/12, p. 19571968, 1991.

YOON, B. Y., LANG, H.J. \& COBB, B. G. Effects of priming on improve germination under stress. Horticultural Science, Calcuta, v.32, n.2, p.383-395, 1997.

YAHIRO, M.; ORYOJI Y. Effects of gibberellin and cytokinin treatments on the promotion of germination in papaya, seeds. Mem Fac Agric, Kagoshima Univ, v.16, p.45-51, 1980. 